$\mathrm{CD} 25+$ regulatory $\mathrm{T}$ cell activity and enhances active immunotherapy against BCR-ABL- tumors. J Immunol 2008; 181:6955-6963.
5. Thachil J. T-regulatory cell response in psoriasis and changes with imatinib therapy. Clin Exp Dermatol 2009;34:e1022.

\title{
A Case of Multiple Desmoplastic Trichoepithelioma
}

\author{
Seong Hun Moon, Hyun Seok Choi, Hyoung Il Kwon, Joo Yeon Ko, Jeong Eun Kim \\ Department of Dermatology, Hanyang University College of Medicine, Seoul, Korea
}

\section{Dear Editor:}

A 23-year-old woman presented with multiple, progressively growing, asymptomatic, depressed macules on face for 2 years. Physical examination revealed three yellowish to skin-colored annular atrophic macules $2 \sim 5 \mathrm{~mm}$ in size without elevated border on both cheeks (Fig. 1). She had no family or past history that scar might occur such as acne, chickenpox, herpes infection or prior laser treatment. Laboratory data including blood cell counts, biochemistry and urinalysis were unremarkable. Histopa- thology showed narrow strands of basaloid tumor cells in a fibrous stroma with adjacent embedded keratinous cysts (Fig. 2). The tumor strands were distributed from the upper to the deeper dermis. We performed additional exicisional biopsy with immunohistochemical staining in order to differentiate from malignant neoplasms including morpheic basal cell carcinoma (BCC) and microcystic adnexal carcinoma (MAC). Carcinoembryonic antigen (CEA), epithelial membrane antigen (EMA), CD23, and CK19 were negative, and CK20 showed focal positive. From these find-
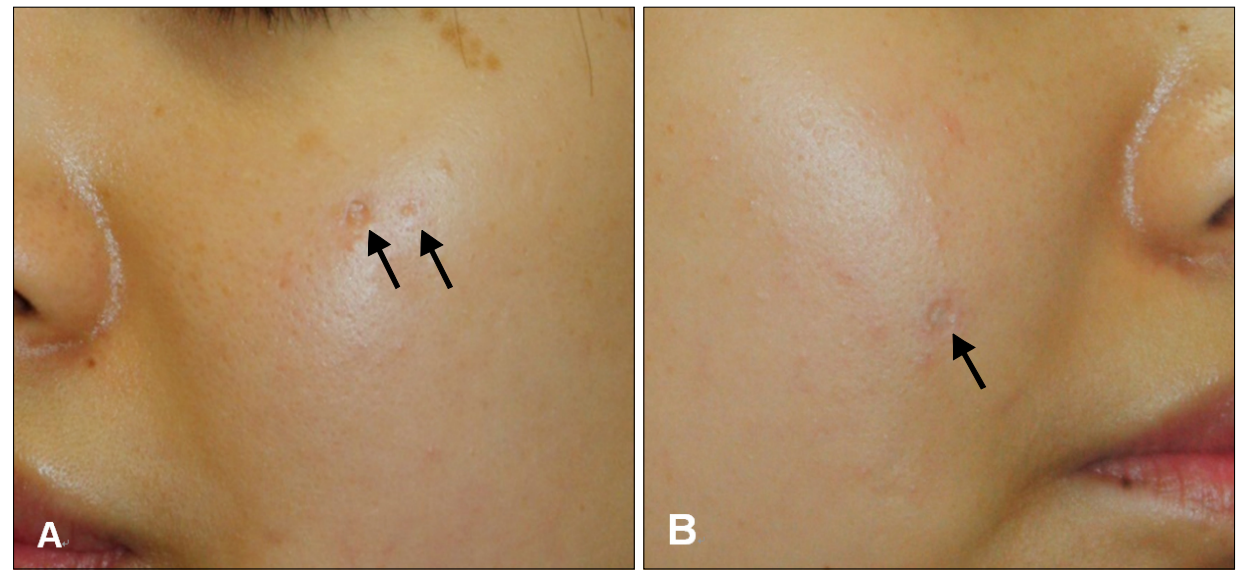

Fig. 1. (A, B) Cutaneous examination revealed multiple yellowish to skin-colored annular, depressed macules on both cheeks.

Received April 27, 2015, Revised June 19, 2015, Accepted for publication July 14, 2015

Corresponding author: Jeong Eun Kim, Department of Dermatology, Hanyang University College of Medicine, 222 Wangsimni-ro, Seongdong-gu, Seoul 04763, Korea. Tel: 82-2-2290-8441, Fax: 82-2-2291-9619, E-mail: dermakim@gmail.com

This is an Open Access article distributed under the terms of the Creative Commons Attribution Non-Commercial License (http://creativecommons.org/ licenses/by-nc/4.0) which permits unrestricted non-commercial use, distribution, and reproduction in any medium, provided the original work is properly cited.

Copyright $($ The Korean Dermatological Association and The Korean Society for Investigative Dermatology 

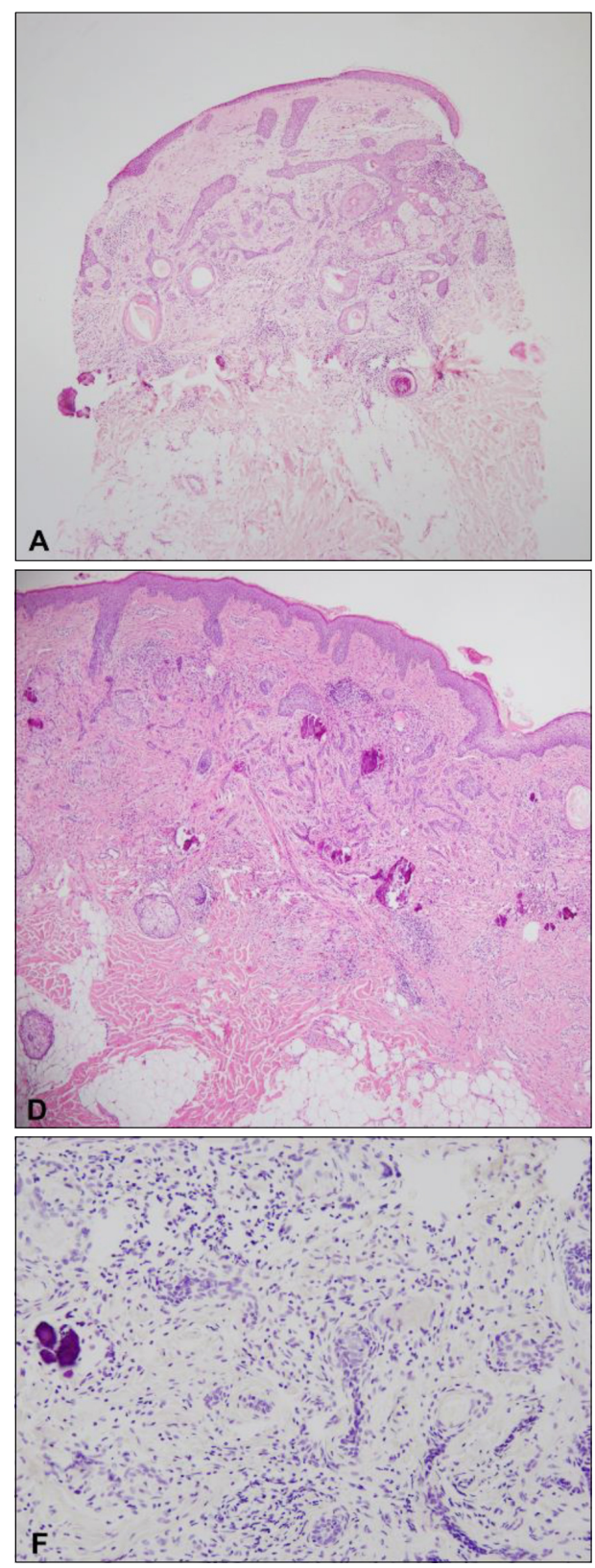
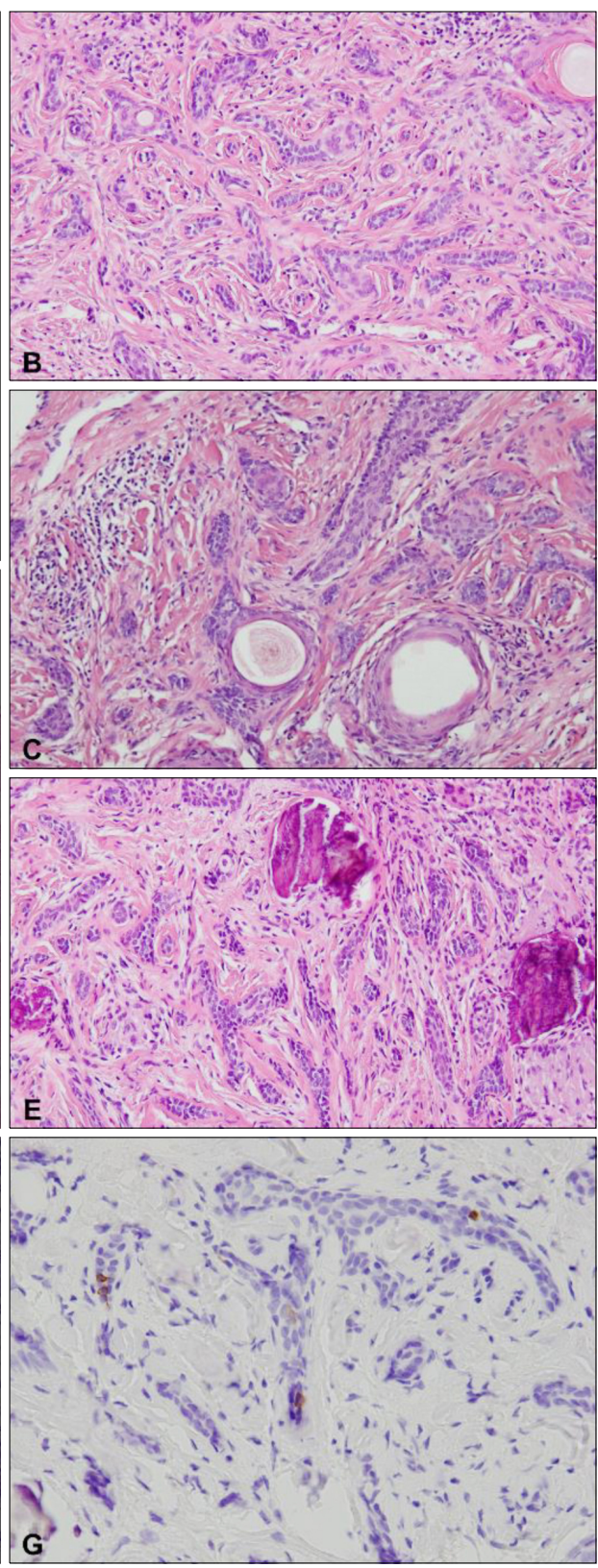

Fig. 2. (A) Biopsy specimen of left cheek reveals atrophic epidermis with upper and mid dermal cellular infiltration $(\mathrm{H} \& \mathrm{E}, \times 40)$. (B) Tumor strands embedded in dense fibrous stroma are composed of small basaloid cells one to two cells thick (H\&E, × 200). (C) Keratinous cysts adjacent to the basaloid cells are observed $(\mathrm{H} \& \mathrm{E}, \times 200)$. (D) Biopsy of a right cheek lesion shows cellular infiltration, horn cysts, and calcifications in upper and mid dermis $(H \& E, \times 40)$. (E) Narrow strands of tumor cells of small basaloid cells with focal calcification are similar to the histopathologic findings of left cheek $(H \& E, \times 200)$. $(\mathrm{F}, \mathrm{G})$ Immunohistochemical staining for CK19 was negative and CK20 showed focal positivity (F: CK10, $\times 200$; G: CK20, × 400). ings, she was diagnosed with desmoplastic trichoepithelioma (DTE), and remaining lesions were completely removed.

DTE is a rare benign skin appendageal neoplasm. It is a distinct variant of trichoepithelioma based upon its unique clinical and histopathological characteristics ${ }^{1}$. Clinically, it typically shows $3 \sim 8 \mathrm{~mm}$ diameter, annular, yellowish or skin-colored asymptomatic plaques, with an elevated border and a depressed or atrophic center on face ${ }^{1}$. It almost develops as a solitary lesion, although rare cases of patients with multiple lesions have been reported ${ }^{2}$.

Histopathologically, DTE is characterized by following features. First, epithelial strands consist of small basaloid cuboidal cells in a one to three-cell-thick layer. Second, many keratinous cysts have a peripheral border of basaloid cuboidal cells, and sometimes have several calcification foci. Finally, stroma appears as dense fibrous stroma ${ }^{1}$. Differential diagnosis includes MAC, BCC, and scar. Although MAC presents with many horn cysts and epithelial cords, it is distinguished by ductal differentiation and infiltration to the subcutis or deeper structures ${ }^{3}$. Therefore, when biopsy is superficial, MAC can be misdiagnosed as DTE ${ }^{3}$. Assessing EMA and CEA immunohistochemistry may identify ductal differentiation and CD23 expression in MAC ${ }^{1}$. CK19 demarcates follicular bulge stem cells and its positivity favors MAC over DTE ${ }^{4}$. Both 
DTE and morpheic BCC can exhibit basaloid cells in strands and sclerotic stroma. However, neither cellular atypia nor peripheral palisading are seen in DTE, and morpheic BCC is not usually associated with horn cyst formation ${ }^{1}$. Also, in most DTE, retained or increased CK20-positive Merkel cells are found, but not in morpheic BCC $^{5}$. Scar should be considered if multiple depressed macules appear, but it can be easily differentiated based upon its histopathology.

The treatment of choice is surgical excision and Mohs micrographic surgery is recommended to achieve clear surgical margins. In our case, because multiple lesions had developed and tumor strands extended into the deep dermis, total excision was performed to exclude malignancy. Therefore, initial proper biopsy is important to make an accurate diagnosis and treatment in patients with multiple scar-like depressed macules on face.

Herein, we report a rare case of multiple DTE, which should be differentiated from malignancy histopathologically. ogy of the skin. 4th ed. Philadelphia: WB Saunders, 2011: 1445-1487.

2. Takiyoshi N, Nakano H, Kaneko T, Aizu T, Nakajima K, Akasaka $\mathrm{E}$, et al. Multiple desmoplastic trichoepitheliomas with ossification and cholesterol deposition. Clin Exp Dermatol 2009;34:634-635.

3. Rustemeyer J, Zwerger S, Pörksen M, Junker K. Microcystic adnexal carcinoma of the upper lip misdiagnosed benign desmoplastic trichoepithelioma. Oral Maxillofac Surg 2013; 17:141-144.

4. Sellheyer K, Nelson P, Kutzner H, Patel RM. The immunohistochemical differential diagnosis of microcystic adnexal carcinoma, desmoplastic trichoepithelioma and morpheaform basal cell carcinoma using BerEP4 and stem cell markers. J Cutan Pathol 2013;40:363-370.

5. Costache $M$, Bresch $M$, Böer A. Desmoplastic trichoepithelioma versus morphoeic basal cell carcinoma: a critical reappraisal of histomorphological and immunohistochemical criteria for differentiation. Histopathology 2008;52:865-876.

\title{
REFERENCES
}

1. Calonje JE, Brenn T, Lazar AJ, McKee PH. McKee's pathol-

\section{A Case of Terra Firma-Forme Dermatosis: Differentiation from Other Dirty-Appearing Diseases}

\author{
Jungyoon Moon, Min-Woo Kim, Hyun-Sun Yoon, Soyun Cho, Hyun-sun Park \\ Department of Dermatology, SMG-SNU Boramae Medical Center, Seoul, Korea
}

Dear Editor:

Terra firma-forme dermatosis (TFFD), which derives its term from the Latin phrase 'terra-firma' meaning dry land, is a rare skin disorder characterized by hyperpigmentation resembling dirt-like brown patches ${ }^{1,2}$. Only small cases have been published, but it is important to understand this

Received June 23, 2015, Revised July 15, 2015, Accepted for publication July 20, 2015

Corresponding author: Hyun-sun Park, Department of Dermatology, SMG-SNU Boramae Medical Center, 20 Boramae-ro 5-gil, Dongjak-gu, Seoul 07061, Korea. Tel: 82-2-870-2880, Fax: 82-2-870-0714, E-mail: snuhdm@gmail.com

This is an Open Access article distributed under the terms of the Creative Commons Attribution Non-Commercial License (http://creativecommons.org/ licenses/by-nc/4.0) which permits unrestricted non-commercial use, distribution, and reproduction in any medium, provided the original work is properly cited.

Copyright (C) The Korean Dermatological Association and The Korean Society for Investigative Dermatology 